\title{
FAKTOR-FAKTOR YANG MEMENGARUHI PRODUKSI USAHATANI KOPI ARABIKA DI LMDH KARAMAT JAYA KECAMATAN CISURUPAN KABUPATEN GARUT
}

\section{FACTORS AFFECTING ARABICA COFFEE FARMING PRODUCTION IN LMDH KARAMAT JAYA CISURUPAN GARUT DISTRICT}

\author{
Nadila Indarwati*, Ahmad Choibar Tridakusumah \\ Program Studi Agribisnis, Fakultas Pertanian, Universitas Padjadjaran \\ *Email: indarwatinadila@gmail.com \\ (Diterima 29-07-2021; Disetujui 15-12-2021)
}

\begin{abstract}
ABSTRAK
Desa Karamatwangi merupakan salah satu sentra penghasil kopi di Kecamatan Cisurupan Kabupaten Garut. Produksi kopi arabika di desa ini patut untuk ditonjolkan terutama mereka sudah dikenal di pasar nasional maupun internasional. Permasalahan yang dihadapi petani kopi antara lain dalam hal penyediaan kuantitas untuk mencukupi kebutuhan pasar internasional. Tujuan penelitian ini adalah untuk menganalisis faktor-faktor yang memengaruhi produksi kopi arabika di LMDH Karamat Jaya. Desain pada penelitian ini menggunakan desain kuantitatif dengan teknik penelitian survei, responden penelitian ini adalah petani kopi anggota LMDH Karamat Jaya serta menggunakan analisis Regresi Linear Berganda. Hasil analisis linear berganda diperoleh pupuk urea, jumlah tanaman dan tenaga kerja merupakan faktor produksi yang paling berpengaruh nyata terhadap produksi. Faktor-faktor lain yang tidak terlalu berpengaruh terhadap produksi kopi arabika adalah luas lahan, pupuk kandang, umur tanaman dan modal.
\end{abstract}

Kata kunci: Faktor Produksi, Usahatani Kopi

\section{ABSTRACT}

Karamatwangi village is one of the coffee-producing centers in The Cisurupan Garut District. Arabica coffee production in this village should be highlighted, especially they are well known in national and international markets. Problems faced by coffee farmers include in terms of providing quantity to meet the needs of the international market. The purpose of this study was to analyze the factors that affect Arabica coffee production in LMDH Karamat Jaya. The design of this study uses a quantitative design with survey research techniques, the respondents of this study are coffee farmers led karamat Jaya members and use analysis of Multiple Linear Regression. The results of multiple linear analyses obtained urea fertilizer, the number of plants, and labor as the most influential production factor to production. Other factors that do not have much effect on arabica coffee production are land area, manure, plant age, and capital.

Keywords: Production Factors, Coffee Farming

\section{PENDAHULUAN}

Salah satu komoditas pertanian yang mempunyai peluang besar dalam pembangunan sektor perkebunan adalah kopi. Tahun 2020 perkebunan kopi
Indonesia mencakup total wilayah kirakira 1,24 juta hektar, 933 hektar perkebunan kopi robusta dan 307 hektar perkebunan arabika. Indonesia baru menghasilkan 12 juta karung kopi 


\section{FAKTOR-FAKTOR YANG MEMPENGARUHI PRODUKSI USAHATANI KOPI ARABIKA \\ DI LMDH KARAMAT JAYA KECAMATAN CISURUPAN KABUPATEN GARUT \\ Nadila Indarwati, Ahmad Choibar}

pertahun, sedangkan negara penghasil terbesar yaitu Brazil mampu memproduksi rata-rata 53 juta karung kopi berukuran $60 \mathrm{~kg}$ pada rentang tahun 2013 hingga $2018^{1}$. Jawa Barat merupakan salah satu sentra produksi yang cocok ditanami kopi. Produksi kopi di Jawa Barat selama bertahun-tahun terus mengalami kenaikan. Tahun 2017 Jawa Barat menghasilkan produksi kopi sebesar 16.768 ton, produksi kopi mengalami kenaikan pada tahun 2018 yaitu mencapai 19.742 ton (BPS, 2018).

Kabupaten Garut merupakan kabupaten dengan luas areal perkebunan rakyat tertinggi kedua di Provinsi Jawa Barat setelah Kabupaten Bandung, yaitu mencapai 4.189 ha dengan produksi mencapai 2.282 ton (BPS, 2016). Garut dikenal sebagai penghasil kopi yang memiliki citarasa aroma yang khas karena berada di wilayah sekitar pegunungan. Kecamatan Cisurupan merupakan salah satu daerah produksi kopi di Kabupaten Garut. Berdasarkan BPS tahun 2020 produksi kopi di Kecamatan Cisurupan mencapai 298,77 ton. Produksi ini masih rendah dari Kecamatan Cikajang yaitu sebesar 447,63

1 Richard Cox,'Kopi", Indonesia-Investments, diakses dari https://www.indonesiainvestments.com/id/bisnis/komoditas/kopi/item 18 $\underline{6}$, pada tanggal 8 Juli 2021 pukul 11.24 ton. Penyebabnya dari kuantitas produksi yang masih rendah dan hasil produksi dalam satu kali panen yang tidak menentu. Dampaknya yakni sulit menyesuaikan antara produksi, kualitas, pengolahan, dan pemasaran kopi arabika serta berdampak juga pada aktivitas usahatani didalamnya termasuk penggunaan faktor produksi (Adinandra et all, 2020).

Desa sentra produksi kopi di Kecamatan Cisurupan yaitu Desa Karamatwangi. Luas wilayahnya lebih dari 175,3 hektare dengan ketinggian > 1200 mdpl. Lokasi perkebunan kopi terletak di Kaki Gunung Papandayan yang merupakan gunung berapi aktif sehingga memiliki unsur hara yang beragam. Dari hasil wawancara diketahui produksi kopi Desa Karamatwangi mengalami peningkatan pada tahun 2020 yaitu sebesar 103,6 ton. Penyebab peningkatan produksi karena pemberlakuan kebijakan penanaman kopi serta pengadaan kegiatan penyuluhan tentang tanaman kopi kepada petani dan bantuan bibit kopi oleh pemerintah Kabupaten Garut sebagai rangkaian kegiatan dalam meningkatkan produksi kopi. Penelitian terdahulu yang menunjukkan bahwa penggunaan faktorfaktor produksi jumlah pupuk, umur 
tanaman, dan jumlah tanaman pada produksi kopi arabika perkebunan rakyat di Kabupaten Dairi berpengaruh positif dan signifikan sedangkan tenaga kerja dan jumlah pestisida belum signifikan (Purba S, 2018). Berdasarkan permasalahan di atas, maka penulis tertarik untuk melakukan penelitian yang berjudul "Faktor-faktor yang Memengaruhi Produksi Usahatani Kopi Papandayan di LMDH Karamat Jaya Kecamatan Cisurupan Kabupaten Garut”..

\section{METODE PENELITIAN}

\section{Tempat dan Objek Penelitian}

Objek penelitian ini adalah faktorfaktor yang memengaruhi produksi usahatani kopi arabika dan biaya produksi kopi. Penelitian ini dilakukan di Desa Karamatwangi, Kecamatan Cisurupan, Kabupaten Garut. Tempat penelitian dipilih karena produksi kopi yang dihasilkan Desa Karamatwangi berjumlah 103,6 ton tertinggi dibandingkan desa-desa disekitarnya.

\section{Desain Penelitian}

Desain penelitian yang digunakan adalah penelitian kuantitatif. Penelitian kuantitatif merupakan metode penelitian yang berlandaskan pada filsafat positivisme, digunakan untuk meneliti pada populasi atau sampel tertentu, pengumpulan data menggunakan instrument penelitian, analisis data bersifat kuantitatif atau statistik, dengan tujuan untuk menguji hipotesis yang telah ditetapkan (Sugiyono,2017).

\section{Variabel Penelitian}

Variabel yang digunakan dalam penelitian ini adalah sebagai berikut :

1. Produksi adalah proses budidaya untuk menghasilkan kopi arabika yang memiliki kualitas serta harga jual yang tinggi ( $\mathrm{kg})$.

2. Luas lahan adalah area/tempat yang digunakan untuk melakukan usahatani atau budidaya di atas sebidang tanah, yang diukur dalam satuan hektar (ha).

3. Pupuk Urea, jumlah pemakaian pupuk urea dalam satu kali musim tanam. Satuan yang digunakan adalah kilogram permusim tanam (kg/MT).

4. Pupuk Kandang, jumlah penggunaan pupuk kandang dalam satu kali musim tanam. Satuan yang digunakan adalah kilogram permusim tanam (kg/MT)

5. Umur Tanaman adalah masa dimulai penanaman hingga waktu dipanen (Tahun).

6. Modal adalah uang yang digunakan untuk membayar faktor-faktor produksi (Rp). 
7. Jumlah tanaman, satuan pohon yang sedang dalam proses pertumbuhan dan belum dapat dipanen atau diambil hasilnya (pohon).

8. Tenaga kerja adalah faktor produksi yang digunakan dalam budidaya kopi arabika dari pengolahan lahan hingga pasca panen. Penggunaan tenaga kerja diukur dalam hari orang kerja (HOK).

\section{Teknik Penarikan Sampel}

Populasi yang digunakan adalah seluruh anggota kelompok tani yang tergabung pada LMDH Karamat Jaya. Penentuan sampel menggunakan rumus slovin. Jumlah populasi pada kelompok tani yaitu 167 orang. Berdasarkan rumus slovin maka ukuran sampel yang digunakan sebagai berikut :

$$
\begin{gathered}
n=\frac{N}{1+N(a)^{2}} \\
n=\frac{167}{1+167(0,1)^{2}} \\
n=63
\end{gathered}
$$

Keterangan :

$n=$ Ukuran sampel

$N=$ Ukuran Populasi

$\alpha=$ standar error yang digunakan $10 \%$

$$
\text { Hasil perhitungan sampel }
$$
menggunakan rumus slovin didapatkan sampel yang berukuran 63 orang anggota LMDH Karamat Jaya sebagai responden.

\section{Teknik Pengumpulan Data}

Teknik pengumpulan data yang digunakan dalam penelitian ini yaitu wawancara, observasi, kuesioner dan kepustakaan. Wawancara merupakan teknik pengumpulan data dengan tanya jawab yang dilakukan untuk memperoleh informasi dan pengetahuan, responden diberikan pertanyaan yang sama dengan panduan kuesioner. Observasi merupakan teknik yang dilakukan dengan mengadakan pengamatan langsung terhadap objek yang akan diteliti. Observasi memerlukan pencatatan dan perekaman yang detail terhadap perilaku informan tentang apa yang terjadi didalam tempat penelitian secara spesifik.

Kuesioner adalah cara memberikan pertanyaan tertulis kepada responden untuk di jawabnya. Kepustakaan merupakan teknik pengumpulan data dengan menggunakan literatur yang berkaitan dengan penelitian. Sumber data bisa didapat dari jurnal, skripsi, BPS, Dinas Pertanian, Outlook Tanaman Hortikultura dan media informasi lainnya yang berkaitan dengan penelitian.

\section{Metode Analisis}

Metode analisis yang digunakan adalah analisis regresi linear berganda (OLS). OLS atau analisis regresi berganda merupakan teknik analisis data 
untuk menganalisis hubungan antara variabel terikat dengan variabel bebas. Dalam penelitian ini, metode OLS digunakan untuk menganalisis faktorfaktor yang memengaruhi produksi usahatani kopi arabika. Model OLS dalam penelitian ini adalah sebagai berikut.

$$
\begin{aligned}
& Y=\beta_{0}+\beta_{1} X_{1}+\beta_{2} X_{2}+\beta_{3} X_{3}+\beta_{4} X_{4}+ \\
& \beta_{5} X_{5}+\beta_{6} X_{6}+\beta_{7} X_{7}+\text { epsilon }
\end{aligned}
$$

Keterangan :

Y : produksi kopi arabika

$\beta_{0} \quad$ : intersep

$\mathrm{X}_{1} \quad$ : Luas Lahan (Ha)

$\mathrm{X}_{2} \quad$ : Pupuk Urea (Kg)

$\mathrm{X}_{3} \quad$ : Pupuk Kandang $(\mathrm{Kg})$

$\mathrm{X}_{4} \quad$ : Umur Tanaman (Tahun)

$\mathrm{X}_{5} \quad$ : Modal (Rp)

$\mathrm{X}_{6} \quad$ : Jumlah Tanaman (pohon)

$\mathrm{X}_{7} \quad$ : Tenaga Kerja (HOK)

epsilon : Standard error

\section{HASIL DAN PEMBAHASAN}

\section{Karakteristik Petani}

Karakteristik petani kopi merupakan perbedaan data pribadi masing-masing petani. Karakteristik ini meliputi umur petani, tingkat pendidikan, pengalaman usahatani, jumlah tanaman, dan status kepemilikan lahan. Berdasarkan data responden terdapat tiga kategori, mayoritas petani berada di usia sangat produktif dengan 51 petani $(81,7 \%)$. Untuk usia produktif berjumlah 7 petani $(10,6 \%)$, sedangkan petani yang sudah memasuki usia tidak produktif berjumlah 5 petani $(7,7 \%)$. Petani di usia sangat produktif dapat meningkatkan produktivitas kerja dengan menerima adopsi inovasi dalam usahatani. Hasil penelitian ini juga selaras dengan Sulistyowati et al. (2015) petani yang usianya semakin tua cenderung menyewakan pohonnya kepada petani lainnya karena kemampuan fisik pada dirinya semakin berkurang.

Pendidikan merupakan salah satu faktor yang memengaruhi perkembangan gaya berpikir dan wawasan. Semakin tinggi tingkat pendidikan, maka semakin tinggi cara berpikir dan kemampuan menganalisis situasi. Mayoritas pendidikan dari petani kopi LMDH Karamat Jaya adalah SD (64,60\%), artinya tingkat pendidikan petani yang ada di LMDH Karamat Jaya masih tergolong rendah.

Dalam berusahatani petani memiliki pengalaman yang berbeda beda. Mayoritas petani LMDH Karamat Jaya memiliki pengalaman dalam berusahatani kurang dari 20 tahun sebanyak 27 petani (41,4\%), artinya petani kopi LMDH Karamat Jaya dalam berusahatani sudah cukup berpengalaman. Untuk 22 petani $(33,8 \%)$ masih kurang tingkat pengalaman 
usahatani kopinya karena baru memulai dalam berusahatani kopi dan hanya satu petani yang memiliki pengalaman lebih dari 50 tahun dalam usahatani kopi. Status kepemilikan lahan petani di LMDH Karamat Jaya adalah milik lahan perhutani. Lokasi untuk bercocok tanam berada di gunung papandayan sehingga wilayah berada di lahan milik perhutani. Penyewaan lahan petani dengan biaya Rp. 10.000/Patok.

\section{Sarana Produksi}

Tanaman kopi menggunakan sarana produksi seperti lahan, bibit, pupuk dan tenaga kerja. Luas lahan pertanian dibagi menjadi 3 kelompok yaitu petani skala kecil dengan luas lahan $(\leq 0,5) \mathrm{Ha}$, lahan skala menengah dengan luas lahan $(0,5-$ 1,0 ha) dan skala besar dengan luas lahan $(\geq 1,1)$ ha (Elfadina, 2019). Luas lahan petani kopi yang dimiliki termasuk kedalam lahan dengan skala kecil dengan jumlah 33 petani $(52,4 \%)$. Urutan kedua luas lahan skala menengah dengan 27 petani $42,9 \%$. Petani yang memiliki luas lahan lebih dari satu hektar hanya berjumlah 3 petani $(4,8 \%)$.

Dalam usahatani kopi di LMDH Karamat Jaya penggunaan tenaga kerja dibagi menjadi dua yaitu, tenaga kerja dalam keluarga dan tenaga kerja luar keluarga. Berdasarkan hasil wawancara dengan petani, upah untuk tenaga kerja pria diberi upah Rp. 40.000/HOK sedangkan untuk wanita $\mathrm{Rp}$. 35.000/HOK. Untuk jam kerjanya dimulai pukul $07.00-16.00$ WIB, sehingga total jam bekerja adalah 8 jam. Mayoritas tenaga kerja paling banyak digunakan waktu kegiatan panen yang berjumlah 220 petani didominasi oleh petani laki-laki(56,8\%) dan 95 petani perempuan $(43,2 \%)$.

Modal yang digunakan oleh petani kopi LMDH Karamat Jaya adalah modal pribadi. Pupuk yang digunakan petani kopi arabika di LMDH Karamat Jaya terdiri dari pupuk organik dan pupuk kimia. Penggunaan pupuk kandang lebih banyak digunakan dengan total $1.100 \mathrm{~kg}$. Untuk pupuk Urea, NPK, dan TSP masing-masing penggunaan pupuk dalam satu musim berjumlah $79 \mathrm{~kg}, 89 \mathrm{~kg}$, dan $93 \mathrm{~kg}$.

\section{Analisis Regresi Linear Berganda}

Fungsi produksi yang digunakan untuk melihat faktor-faktor yang memengaruhi usahatani kopi adalah fungsi regresi linear berganda dengan variabel terikat yaitu produksi kopi (Y) dan variabel bebas yaitu luas lahan (X1), bibit (X2), pupuk urea (X3), pupuk kandang (X4), umur tanaman (X5), modal (X6) dan tenaga kerja (X7). Dari 
hasil perhitungan menggunakan SPSS versi 26 didapatkan hasil sebagai berikut Tabel 1.

Tabel 1. Faktor-faktor yang memengaruhi produksi kopi arabika

\begin{tabular}{clrc}
\hline No & \multicolumn{1}{c}{ Variabel } & Koefisien & $\begin{array}{c}\text { Signi- } \\
\text { fikan }\end{array}$ \\
\hline 1. & Konstanta $(\mathrm{C})$ & 763,496 & 0,155 \\
\hline 2. & Luas Lahan & 596,502 & 0,084 \\
\hline 3. & Pupuk Urea & 0,901 & 0,007 \\
\hline 4. & Pupuk Kandang & 0,000 & 0,249 \\
\hline 5. & Umur Tanaman & 21,231 & 0,939 \\
\hline 6. & Modal & 0,000 & 0,850 \\
\hline 7. & Jumlah Tanaman & 0,320 & 0,000 \\
\hline 8. & Tenaga Kerja & 38,588 & 0,048 \\
\hline & R - Square & 0,619 & \\
\hline & Uji F & 12,756 & 0,000 \\
\hline
\end{tabular}

Berdasarkan hasil regresi linear pada Tabel 1, nilai $\mathrm{R}$-square adalah 0,619. Nilai ini menunjukkan bahwa variabel dependen produksi kopi arabika secara umum dapat dijelaskan oleh variabel-variabel di dalam model yaitu sebesar $61,9 \%$. Sedangkan sisanya $38,1 \%$ dijelaskan oleh variabel lain di luar model tersebut seperti cuaca, hama dan penyakit. Berdasarkan Tabel 1, nilai Uji $F$ adalah 0,000 dengan tingkat signifikan 0,05. Maka dapat disimpulkan bahwa variabel luas lahan, pupuk urea, pupuk kandang, umur tanaman, modal dan tenaga kerja berpengaruh nyata terhadap produksi kopi arabika.

Variabel luas lahan memiliki nilai signifikansi 0,084 ( $\mathrm{p}>0,05)$, maka dapat disimpulkan bahwa luas lahan tidak berpengaruh nyata terhadap produksi kopi arabika. Dari hasil wawancara, petani kopi arabika menggunakan sistem pola tanam tumpang sari dengan tanaman sayuran sehingga menyebabkan lahan tidak berpengaruh nyata terhadap peningkatan produksi kopi arabika.

Variabel pupuk urea memiliki nilai signifikansi $0,007(\mathrm{p}<0,05)$, artinya penggunaan input pupuk urea di tanaman kopi menunjukan pengaruh yang signifikan terhadap hasil produksi. Nilai koefisien pupuk urea yaitu 0,901 artinya setiap penambahan tenaga kerja sebesar $1 \%$ dengan menganggap faktor lain tetap, maka penambahan tenaga kerja akan meningkatkan produksi kopi arabika sebesar $0,9 \%$. Hasil ini selaras dengan penelitian Sudaryati, (2004) dari hasil penelitian dapat dilihat bahwa penggunaan pupuk berpengaruh nyata terhadap produksi kopi.

Pupuk Kandang didapatkan dari kotoran ayam, sapi ataupun hewan ternak yang dimiliki petani. Harga pupuk kandang jauh lebih terjangkau daripada pupuk kimia. Dosis yang digunakan dalam pupuk kandang rata-rata lebih banyak dari pupuk kimia. Variabel pupuk kandang memiliki nilai signifikansi 0,249 ( $p>0,05)$, dapat dikatakan bahwa pupuk kandang tidak berpengaruh nyata terhadap peningkatan produksi kopi arabika. 


\section{FAKTOR-FAKTOR YANG MEMPENGARUHI PRODUKSI USAHATANI KOPI ARABIKA \\ DI LMDH KARAMAT JAYA KECAMATAN CISURUPAN KABUPATEN GARUT \\ Nadila Indarwati, Ahmad Choibar}

Variabel umur tanaman memiliki nilai signifikansi $0,939(\mathrm{p}>0,05)$, maka disimpulkan bahwa umur tanaman tidak berpengaruh nyata terhadap produksi kopi arabika. Berdasarkan wawancara dengan petani umur tanaman kopi baru memasuki usia produktif yaitu berumur dua tahun sehingga hasil panen masih rendah. Umur tanaman lima tahun keatas bisa menghasilkan produksi yang maksimal.

Variabel modal memiliki signifikansi $\quad 0,850 \quad(p>0,05), \quad$ artinya penggunaan input modal di tanaman kopi tidak berpengaruh nyata terhadap produksi kopi arabika. Modal terbesar hanya dikeluarkan pada saat awal penanaman kopi selanjutnya modal yang dikeluarkan hanya untuk biaya tenaga kerja pemangkasan, panen dan pembelian pupuk.

Variabel jumlah tanaman memiliki nilai signifikansi $0,000(\mathrm{p}<0,05)$, maka disimpulkan bahwa jumlah tanaman berpengaruh nyata terhadap produksi kopi arabika. Nilai koefisien jumlah tanaman yaitu 0,320 artinya apabila variabel jumlah tanaman ditambah sebesar 1\% maka akan menyebabkan terjadi penambahan produksi tanaman kopi arabika sebesar $0,32 \%$ dengan asumsi variabel lain dianggap tetap.
Berdasarkan hasil penelitian diketahui bahwa rata-rata populasi tanaman kopi arabika adalah 900 tanaman per hektar dengan jarak tanam rata-rata 2,5 x 2,5 m. Jarak tanam yang dilakukan petani sudah sesuai dengan rekomendasi yang dianjurkan oleh dinas pertanian kabupaten garut yaitu jarak tanam kopi $2,5 \mathrm{~m} \times 2,5 \mathrm{~m}$.

Semakin tinggi jumlah tanaman maka semakin tinggi produksi yang dihasilkan. Walaupun produktivitas kopi arabika masih tergolong rendah yaitu 13,7 kw/ha/tahun kopi arabika, apabila dibandingkan dengan produksi nasional yaitu bisa mencapai $15-20 \mathrm{kw} / \mathrm{ha} / \mathrm{tahun}$. Peningkatan jumlah tanaman juga harus diseimbangi dengan kualitas bibit yang unggul agar dapat menghasilkan produksi yang tinggi. Hal ini sejalan dengan penelitian Isyariansyah, (2015) bahwa jumlah pohon secara parsial berpengaruh nyata terhadap produksi kopi.

Variabel tenaga kerja memiliki nilai signifikansi 0,048 ( $\mathrm{p}<0,05)$, maka disimpulkan bahwa tenaga kerja berpengaruh nyata terhadap produksi kopi arabika. Nilai koefisien tenaga kerja yaitu 38.588 artinya setiap penambahan tenaga kerja sebesar $1 \%$ dengan menganggap faktor lain tetap, maka penambahan tenaga kerja akan 
meningkatkan produksi kopi arabika sebesar 38,5\%. Dalam program intensifikasi kopi penambahan tenaga kerja dalam pemeliharaan terutama dalam pemangkasan dan pemupukan dapat meningkatkan produksi kopi arabika. Berdasarkan hasil penelitian dan wawancara diketahui tenaga kerja banyak digunakan dalam proses pemanenan bukan untuk perawatan dan pemeliharaan kopi, sehingga perlu diperhitungkan penggunaan dan penambahan jumlah tenaga kerja agar peningkatan produksi dapat tercapai.

\section{KESIMPULAN DAN SARAN}

\section{Kesimpulan}

Faktor produksi yang paling berpengaruh nyata terhadap produksi kopi adalah pupuk urea, jumlah tanaman dan tenaga kerja. Semakin tinggi jumlah tanaman maka semakin tinggi produksi yang dihasilkan. Peningkatan jumlah tanaman juga harus diseimbangi dengan kualitas bibit yang unggul agar dapat menghasilkan produksi yang tinggi. Peningkatan jumlah tenaga kerja akan dapat meningkatkan produksi. Penambahan tenaga kerja dapat meningkatkan produksi kopi arabika dengan kontribusi pada kegiatan pemupukan dan pemanenan buah kopi yang membutuhkan banyak tenaga kerja. Faktor-faktor lain yang tidak terlalu berpengaruh terhadap produksi kopi arabika adalah luas lahan, pupuk kandang, umur tanaman dan modal.

\section{Saran}

1. Untuk meningkatkan produksi kopi arabika disarankan kepada petani untuk meningkatkan populasi tanaman kopi, pemberian pupuk dengan dosis yang tepat, dan untuk tenaga kerja perlu diadakan pembinaan agar dapat meningkatkan produktivitas tenaga kerja sehingga dapat meningkatkan produksi kopi arabika

2. Penelitian ini hanya terbatas pada faktor-faktor yang berpengaruh pada produksi kopi. Perlu dilakukan penelitian lanjutan terkait produksi dengan pemberdayaan, produksi dengan modal sosial ataupun pemasaran produksi kopi arabika.

\section{DAFTAR PUSTAKA}

BPS. (2016). Luas Areal dan Produksi Tanaman Kopi menurut Kepemilikan Jawa Barat. Badan Pusat Statistika.

.(2016). Produksi Tanaman Perkebunan Rakyat Menurut Jenis Komoditi di Kabupaten Garut. Badan Pusat Statistika. 


\section{FAKTOR-FAKTOR YANG MEMPENGARUHI PRODUKSI USAHATANI KOPI ARABIKA \\ DI LMDH KARAMAT JAYA KECAMATAN CISURUPAN KABUPATEN GARUT \\ Nadila Indarwati, Ahmad Choibar}

(2016). Produksi Tanaman Perkebunan Rakyat Menurut Jenis Komoditi di Kabupaten Garut. Badan Pusat Statistika.

.(2018). Statistik Kopi Indonesia. Badan Pusat Statistika. .(2018). Cikajang dalam Angka 2018. Badan Pusat Statistik. .(2021). Kabupaten Garut dalam Angka 2021. Garut : Badan Pusat Statistik.

BPP. (2020). Kecamatan Cisurupan : Desa Karamatwangi

Sugiyono. 2017. Metode Penelitian Kuantitatif. Bandung: Alfabeta.

Sudaryati, E. (2004) . Faktor- faktor yang Memengaruhi Produksi Kopi Rakyat di Kabupaten Temanggung, Universitas Diponegoro, Semarang.

Deviani, F., Rochdiani, D., \& Saefudin, B. R. (2019). Analisis FaktorFaktor yang Memengaruhi Produksi Usahatani Buncis Di Gabungan Kelompok Tani Lembang Agri Kabupaten Bandung Barat. Agrisocionomics: Jurnal Sosial Ekonomi Pertanian, 3(2), 165-173.
Adinandra, R., \& Pujianto, T. 2020. Analisis Sistem Produksi Kopi Menggunakan Good Agriculture Practices. Jurnal Ekonomi Pertanian dan Agribisnis, 4(2), 288297.

Sulistyowati, L., Natawidjaja, R. S., \& Rahmat, B. (2015). Adoption of Technology and Economics Efficiency of The Smallholder Mango Farmers in Indonesia. International Journal of Applied Business and Economic Research (Ijaber), 13(7), 4621-4645. Serial Publication PVT. LTD. New Delhi. India

Elfadina, E. ., Rasmikyatai, E., \& Saefudin, B. (2019). Analisis Luas dan Status Penguasaan Lahan Petani Mangga Dikaitkan dengan Perilaku Agribisnisnya di Kecamatan Cikedung Kabupaten Indramayu. Jurnal Ilmiah Mahasiswa.

Purba, S. (2018). Faktor-Faktor yang Memengaruhi Produksi Kopi Arabika Perkebunan Rakyat di Kabupaten Dairi. 